\title{
Health inequalities in ageing societies
}

\author{
Olaf von dem Knesebeck
}

Published online: 18 May 2010

(C) Swiss School of Public Health 2010

The age distribution of the world's population is undergoing a profound transformation. As mortality and fertility have fallen, the age distribution has been shifting gradually to older ages (UN 2007). In the next 45 years, the global population aged 60 years and above will triple. By 2050, one-third of the European population will be aged 60 and above. In low- and middle-income countries, the proportion of older people is growing even faster than in highincome countries (WHO 2008).

According to the WHO Commission on Social Determinants of Health, global population ageing makes exploring and understanding social determinants of health among older people an increasingly important challenge (WHO 2008). While this issue was neglected by social epidemiology for a long time, gerontological results indicating that old age is not a uniform phase of life, but characterised by social differences have led to an increasing interest. Today there are some studies describing health inequalities in older populations (e.g. McMunn et al. 2006). Overall, these studies indicate that there is also a social gradient in health among older people, although health inequalities tend to be smaller than among middle-age groups. In the following, three important open issues

Olaf von dem Knesebeck is head of the Department of Medical Sociology at the University Medical Center Hamburg-Eppendorf. He is interested in research on social determinants of health and health services research, both with a special focus on older ages and international comparisons.

This Editorial belongs to the series "Social determinants of health".

O. von dem Knesebeck ( $\square$ )

Department of Medical Sociology, University Medical Center Hamburg-Eppendorf, Martinistr. 52, 20246 Hamburg, Germany e-mail: o.knesebeck@uke.uni-hamburg.de concerning health inequalities in ageing societies are outlined.

First, it can be questioned whether standard measures of socio-economic position like education, occupational class, and income are appropriate for older people. There is an intense discussion in sociology of ageing about concepts and measures of social inequality in older ages. While this debate continues, it has been suggested that (a) studies should focus on a set of measures rather than a single indicator to explore the multi-dimensional nature of socioeconomic position in later life, and (b) studies should include indicators, such as assets or home ownership that can be expected to reflect economic advantages or disadvantages accumulated over the life course (Knesebeck et al. 2007; for a general discussion of measurement of social determinants see also McQueen 2009).

Second, as it is still unclear how and why health inequalities vary with age, it seems important to intensify the integration of life course approaches into social epidemiology (Blane 2006; Power and Kuh 2006). These approaches highlight the role of the accumulation of disadvantage over the life course-combining the amount of time different people have spent in more or less disadvantaged circumstances. Health inequality between social groups in this regard is a result of inequalities in the accumulation of social, psychological, and biological advantages and disadvantages over time. Life course approaches help to understand how these social, psychological, and biological factors operating at different stages of the life course contribute to the development of health inequalities in later life.

Third, while there are an increasing number of studies describing health inequalities in older ages, there is not much known about the specific factors contributing to these health inequalities. Moreover, it is not certain whether the 
major explanatory mechanisms (material, behavioural, and psychosocial factors) that were mainly examined in studies focussing on the middle age are equally important in older populations. Material factors like poor housing, unequal access to and quality of health care or physical hazards at work were found to account for a large amount of health inequalities (van Oort et al. 2005; Skalická et al. 2009). However, these studies do not analyse the contribution in different age groups. In terms of behavioural factors, longitudinal analyses of the SHARE dataset (Survey of Health, Ageing, and Retirement in Europe) reveal educational differences in risk behaviour among older people, but these differences only marginally contribute to the explanation of health inequalities (Kok et al. 2008). Psychosocial explanations focus on the unequal distribution of factors, such as social relationships (social networks and social support) and psychosocial stress at work. As the majority of older people is not working, social relationship is expected to be an important explanatory psychosocial factor in this particular age group. However, results of respective studies do not support this hypothesis (Knesebeck 2005). It is an important task for future studies dealing with health inequalities in older populations to explore the specific underlying explanatory mechanisms. To this end, it is useful to include concepts and approaches provided by gerontology and sociology of ageing. In this regard, exploring the social determinants of health among older people is a major challenge and an interdisciplinary task for the future (WHO 2008).

\section{References}

Blane D (2006) The life course, the social gradient, and health. In: Marmot M, Wilkinson R (eds) Social determinants of health. University Press, Oxford, pp 54-77
Knesebeck Ovd (2005) Die Bedeutung sozialer Beziehungen für den Zusammenhang zwischen sozialer Ungleichheit und Gesundheit im Alter. Soz Praventivmed 50:311-318

Knesebeck Ovd, Wahrendorf M, Hyde M, Siegrist J (2007) Socioeconomic position and quality of life among older people in 10 European countries: results of the SHARE study. Ageing Soc 27:269-284

Kok R et al (2008) The association between socioeconomic status and changes in health in Europe. In: Börsch-Supan A (ed) Health, ageing and retirement in Europe (2004-2007): starting the longitudinal dimension. Strauss, Mannheim, pp 123-128

McMunn A, Breeze E, Goodman A, Nazroo J, Oldfield Z (2006) Social determinants of health in older age. In: Marmot M, Wilkinson R (eds) Social determinants of health. University Press, Oxford, pp 267-296

McQueen DV (2009) Three challenges for the social determinants of health pursuit. Int. J Public Health 54:1-2

Power C, Kuh D (2006) Life course development of unequal health. In: Siegrist J, Marmot M (eds) Social inequalities in health. University Press, Oxford, pp 27-53

Skalická V, van Lenthe F, Bambra C, Krokstad S, Mackenbach J (2009) Material, psychosocial, behavioural and biomedical factors in the explanation of relative socio-economic inequalities in mortality: evidence from the HUNT study. Int. J Epidemiol 38:1272-1284

UN (2007) World Economic and Social Survey 2007. Development in an Ageing World. New York: United Nations

van Oort F, van Lenthe F, Mackenbach J (2005) Material, psychosocial, and behavioural factors in the explanation of educational inequalities in mortality in the Netherlands. J Epidemiol Community Health 59:214-220

WHO Commission on Social Determinants of Health (2008) Closing the gap in a generation. Health equity through action on the social determinants of health. WHO, Geneva 